\title{
ASPECTOS INTERFERENTES NA QUALIDADE DO CURSO DE EDUCAÇÃO FÍSICA NA ÓTICA DO CORPO DISCENTE
}

\author{
Marcelo Moreira Antunes* \\ Marcos Doederlein Polito** \\ HELDER GUERRA DE RESENDE***
}

Recebido em: 13 de dezembro de 2009

Aprovado em: 29 de março de 2010

\begin{abstract}
*Mestre em Educação Física pela Universidade Gama Filho (2008). Atualmente é professor da Prefeitura Municipal de Niteroi e professor assistente e coordenador adjunto do curso de graduação em Educação Física do Centro Universitário da Cidade - Rio de Janeiro. E-mail: antunesmm@hotmail.com

**Doutor Educação Física pela Universidade Gama Filho (2006). Atualmente é Professor Adjunto do Departamento de Educação Física da Universidade Estadual de Londrina, coord. do Grupo de Estudo e Pesquisa em Respostas Cardiovasculares e Exercício (GECardio/UEL) e vice-coordenador do programa de pós-graduação Stricto Sensu em Educação Física UEM/UEL. E-mail: marcospolito@uel.br

***Doutor/Livre-Docente em Educação Física - Didática da Educação Física - pela Universidade Gama Filho (1992). Atualmente é Vice-Reitor de Pós-graduação, Pesquisa e Extensão da Universidade Castelo Branco (UCB-RJ). Avaliador de Cursos de Graduação em Educação Física (INEP), tendo presidido a Comissão de Especialistas em Educação Física que subsidiou o CNE na definição das Diretrizes Curriculares Nacionais para os Cursos de Graduação em Educação Física. E-mail: heldergr@globo.com
\end{abstract}

Resumo: O presente estudo objetivou identificar os aspectos que estão interferindo na qualidade do processo de formação acadêmico-profissional de um Curso de Educação Física da cidade do Rio de Janeiro de forma positiva ou negativa, considerando as opiniões de seu corpo discente. Para isso se utilizou a Técnica Dephi em dois rounds. No primeiro round 68 alunos listaram aspectos positivos e aspectos negativos do referido curso. No segundo round 407 informantes responderam a escala de opinião previamente construída, onde avaliaram se os indicadores listados eram positivos ou negativos, e ainda se eram muito ou pouco interferentes em sua formação acadêmico-profissional. Os resultados permitiram verificar que algumas categorias de análise foram predominantemente negativas, por exemplo, a biblioteca e o laboratório de informática. Entretanto a maioria das categorias demonstrou comportamento positivo. Deste modo os aspectos positivos foram predominantes sobre os negativos para essas categorias de análise. Identificou-se ainda que todos os indicadores eram muito interferentes na formação acadêmico-profissional para a maioria dos informantes.

Palavras chaves: Educação física. Avaliação do ensino superior. Técnica delphi.

\section{INTERFERING ASPECTS ON THE QUALITY OF THE PHYSICAL EDUCATION COURSE IN THE PERSPECTIVE OF STUDENTS}

\begin{abstract}
The current research focuses in identifying different aspects influencing the quality of the Physical Education Course of Rio de Janeiro city in a positive or negative way - considering the student's point of view. The Dephi Technique was used for that purpose in two rounds. In the first round 68 students listed positive and negative aspects about the course. In the second round, 407 subjects answered the opinion scale, where they evaluated if the aspects were positive or negative and how impacting they were in influencing their academic and professional formation. With the results, there was possible to verify that some of the aspects were predominantly negative - the library and the computer laboratory for example. Eventually, most of the categories showed positive results. There was concluded that the positive aspects were predominant over the negatives in these categories and that all of these were also very influencing in the academic and professional formation for most of the subjects.
\end{abstract}

Key words: Physical education. Evaluation of the university's course. Delphi technique. 


\section{INTRODUÇÃO}

A avaliação das condições de oferta no ensino superior brasileiro vem se tornando um tema recorrente e objeto de debates por parte da comunidade acadêmica e, em especial, aquela vinculada às instituições de ensino superior. Este cenário de debates, de propostas e de realizações ganhou corpo, mais especificamente, a partir da promulgação da última Lei de Diretrizes e Bases da Educação Nacional (LDB no 9.394/96), que determina que o Estado é o responsável em promover os processos avaliativos da educação, visando a melhoria e a consolidação da qualidade do ensino.

A consolidação desse processo de mudança no campo da avaliação surge a partir da Lei ${ }^{\circ}$ 10.861/2004, que instituiu o Sistema Nacional de Avaliação da Educação Superior (SINAES), que ainda determina que as IES devem idealizar, planejar e realizar seu sistema de auto-avaliação.

Em geral, as IES utilizam instrumentos de auto-avaliação, para a coleta de dados junto ao corpo discente, construídos a partir dos focos de interesse e das necessidades de cada uma delas, o que nem sempre contempla todas as opiniões e críticas julgadas mais importantes pelo corpo discentes. Com essa afirmação não se quer negar que os instrumentos de avaliação elaborados pelas IES possuem importância. Porém, consideramos relevante que os alunos possam expor suas opiniões de forma espontânea sobre as condições e a qualidade do curso ao qual estão vinculados.

O presente estudo justifica-se, por representar uma significativa contribuição para o campo da avaliação do ensino superior, tanto pela utilização do corpo discente como fonte de dados do proceso avaliativo, quanto em estudos que utilizarem a Técnica Delphi em suas metodologias.

Considerando a situação problema configurada, o presente estudo tem por objetivo identificar e categorizar os aspectos interferentes na qualidade do Curso de Graduação em Educação Física de uma Intituição de Ensino Superior (IES) da cidade do Rio de Janeiro, sob a ótica do corpo discente.

A questão que configura o problema a ser investigado pode ser assim destacada: Quais os aspectos que estão interferindo na qualidade do processo de formação acadêmico-profissional do Curso de Educação Física considerando as opiniões de seu corpo discente?

Para responder este problema, é necessário responder as seguintes questões, considerando a opinião consensual de seu corpo discente: Quais aspectos interferem negativamente na qualidade do Curso de Graduação em Educação Física da IES pesquisada? Quais aspectos interferem positivamente na qualidade do Curso de Graduação em Educação Física da IES pesquisada? Que categorias 
do processo de formação acadêmico-profissional ${ }^{1}$ são privilegiadas, em termos positivo e negativo, a partir da opinião dos alunos? Quais os acordos e as diferenças de opinião entre os alunos sobre aspectos que interferem, muito ou pouco, na qualidade do curso? As opiniões dos alunos diferem em função do período em que se encontram no curso, da faixa-etária do grupo de alunos, do turno ao qual estão vinculados e do número de reprovações?

A escolha de uma única instituição para realização do estudo pode-se justificar apoiando-se em Balzan (2000) quando afirma que o conhecimento de uma situação real de uma instituição ou do sistema nacional de ensino superior é fundamental para a implementação das mudanças necessárias para a melhoria da qualidade do ensino.

\section{METODOLOGIA DESENVOLVIDA PARA A REALIZAÇÃO DA PESQUISA}

O presente estudo se caracteriza como uma pesquisa de levantamento de opiniões do tipo survey, sendo descritivo, de natureza quantitativa, pois é realizado no ambiente onde os fatos a serem pesquisados se efetivam.

As pesquisas do tipo levantamento também são conhecidas como survey. Thomas e Nelson (2002) ressaltam que o survey é um método de pesquisa descritivo largamente utilizado, sendo a Técnica Delphi ${ }^{2}$ uma delas. Deste modo a técnica de coleta de dados utilizada no presente estudo é a Técnica Delphi, por se caracterizar como uma forma de encontrar consenso entre os informantes sobre aspectos relevantes da sua realidade. (THOMAS; NELSON, 2002)

Para Linstone e Turoff (1975) a Técnica Delphi pode ser aplicada em uma grande variedade de áreas, incluindo a educação. Segundo Afonso (1992), a Técnica Delphi se concretiza como uma excelente ferramenta para estudos na área da educação e da educação física. Afonso (1992) ressalta ainda a validade e a aplicabilidade da técnica por diversos pesquisadores da área esportiva e pedagógica nas últimas décadas (SMITH, 1974; CHAI, 1976; HARTMAN, 1981; SHEFIELD, 1982; NAHAS, 1988; CARDOSO, 1991 apud AFONSO, 1992). Podem-se citar, ainda, publicações mais recentes que reforçam essa validade e aplicabilidade na área, como as de autoria de Nascimento (1999); Saeta,

1 Coordenação do Curso; Organização curricular; Estágios supervisionados obrigatórios, Práticas pedagógicas obrigatórias como componente curricular; Trabalho de conclusão de curso; Atividades complementares obrigatórias; Desempenho dos alunos no ENADE; Corpo docente; Corpo discente; Corpo técnico-administrativo; Biblioteca; Laboratório de informática; Instalações gerais da Unidade Praça Seca; Recursos materiais e instalações específicas do curso; e Serviços gerais prestados pela Instituição.

2 Apesar dos autores citados neste texto, por vezes, utilizarem o termo Método Delphi, optamos pelo termo Técnica Delphi, pois entendemos que ela é um instrumento e não um conjunto de instrumentos, sendo assim ela se caracteriza como técnica e não método. 
Popadiuk e Teixeira (2003); Hanashiro, Nassif e Teixeira (2003); Nascimento, Nahas e Mendes (2005) e Olarte (2006).

Ali (2005) destaca ainda o caráter qualitativo quando afirma que as atuais pesquisas demonstram a efetividade da Técnica Delphi como um método qualitativo na busca do esclarecimento de pontos específicos.

Para o presente estudo foi utilizado a Técnica Delphi em dois rounds consecutivos para se alcançar um consenso entre os informantes do grupo selecionado. O número de alunos matriculados e freqüentando regularmente o curso é de $847^{3}$, distribuidos entre os turnos da manhã (331 alunos), da tarde (167 alunos) e da noite (349 alunos), divididos entre os oito períodos, o que representou a população do estudo.

Uma amostra composta por 68 alunos foi utilizada para o primeiro round, distribuídos da seguinte forma: 34 do sexo masculino e 34 do feminino, dos três turnos do curso. Os alunos do $1^{\circ}$ período foram descartados por terem pouca Vicência no curso. A amostra utilizada para o segundo round foi de 407 informantes representando $48 \%$ da população.

$\mathrm{O}$ instrumento utilizado no primeiro round foi uma entrevista composta por duas perguntas principais, respondidas pelos informantes para elaboração de uma lista de aspectos positivos e negativos que interferem decisivamente na qualidade da formação acadêmico-profissional. As perguntas eram: (1) Quais os itens que em sua opinião estão interferindo positiva e decisivamente em sua formação acadêmico-profissional; (2) Quais os itens que em sua opinião estão interferindo negativa e decisivamente em sua formação acadêmico-profissional. Os 332 itens informados pelos alunos no primeiro round foram analisados e depurados, resultando em 76 indicadores para constituir o instrumento de coleta dos dados referentes ao segundo round.

Para o segundo round, o instrumento de coleta de dados foi uma escala de opiniões, composto de duas partes: a primeira com informações referentes à caracterização dos informantes, tais como o ano e o semestre de matrícula, idade, o período que cursa, o turno que freqüenta e o número de reprovações ${ }^{4}$. A segunda parte foi composta pela lista de 76 indicadores identificados no primeiro round.

Antes da aplicação final do instrumento, foi realizado um teste de reprodutibilidade. Um grupo formado por 20 alunos foi escolhidos de forma acidental para testar a reprodutibilidade do instrumento. Esse número de alunos foi

3 Dados fornecidos pela diretoria de unidade da Praça Seca referente ao segundo semestre de 2007 através de relatório próprio de alunos ativos.

4 A variável número de reprovações parece relevante no sentido de que pode indicar uma visão tendenciosa do aluno sobre a realidade do curso em sua avaliação. 
determinado tendo como referência o cálculo da amostra para uma análise de correlação, considerando nível de significância menor que 0,05 ; coeficiente de correlação 0,80 ; e potência estatística 0,80 . O cálculo para o número da amostra foi realizado no aplicativo Primer of Biostatistic 4.0.

A análise estatística utilizada foi a correlação não paramétrica de Spearman. Em mais de $70 \%$ das questões aplicadas aos alunos, o coeficiente de correlação mostrou-se superior a 0,80. Esse resultado indicou um alto índice de reprodutibilidade do questionário.

Para cada indicador da escala de opiniões os alunos que responderam ao segundo round tinham que assinalar um dos três critérios de cada uma das duas colunas propositivas A e B.

Na Coluna A a proposição é: o indicador refere-se a um aspecto positivo ou negativo do Curso Educação Física das sua IES? E os critérios correspondentes devem ser: Positivo (+), Negativo (-) ou Sem Opinião Formada (SOF). $\mathrm{Na}$ coluna $\mathrm{B}$ a proposição é: com que ênfase o indicador está interferindo na qualidade de formação do Curso de Educação Física da sua IES? E os critérios correspondentes podem ser: Muito, Pouco ou Sem Opinião Formada (SOF).

O tratamento estatístico utilizado é de característica descritiva, sedimentado no percentual de cada fator interferente identificado. O percentual de $70 \%$ foi estabelecido como linha de corte para a definição de consenso da avaliação dos indicadores. Realizou-se ainda uma análise de regressão múltipla, modelo stepwise. Os dados foram analisados através do programa Statistica 6.0 (Statsoft, Tulsa, USA), considerando como nível de significância estatística o valor de $p$ menor que 0,05 . Objetivou-se com isso a inferência de possíveis associações, isoladas ou combinadas, das variáveis período cursado, faixa-etária, turno e reprovação.

\section{APRESENTAÇÃO E DISCUSSÃO DOS RESULTADOS}

No que se refere a distribuição dos alunos pelos turnos, predominam as matrículas no turno da noite com $41,2 \%$ do corpo discente ativo, ficando $39 \%$ para o turno da manhã e 19,7\% para o turno da tarde. As matrículas noturnas estão coerentes com as apresentadas nos dados sobre as matriculas por turno do Resumo técnico do Censo de 2008 realizado pelo INEP (BRASIL, 2009), que registra $70,9 \%$ das matrículas no turno da noite em nível nacional nas IES privadas.

Seguindo a tendência das matrículas por turno, os alunos vinculados ao turno da noite foram os que mais contribuíram como informantes desta pesquisa, representando $41,3 \%$ dos respondentes. O turno da manhã ficou com $36,6 \% \mathrm{e}$ o da tarde com $22,1 \%$. 
O grupo de informantes foi constituído por 163 mulheres e 244 homens, distribuídos em diversas faixas-etárias. Os dados ainda revelam que o maior quantitativo de informantes está na faixa-etária de 20 a 29 anos $(89,1 \%)$. Estes dados são coerentes com os registrados pelo INEP no ensino superior brasileiro, onde a faixa-etária é de 18 a 24 anos, sendo que 49,4\% dessas matrículas estão distribuídas pela região sudeste. (BRASIL, 2005)

O número de reprovações nas disciplinas do Curso revelaram que 55,2\% dos informantes nunca foram reprovados; que $25 \%$ foram reprovados apenas uma vez; que $10 \%$ foram reprovados duas vezes; que $5,4 \%$ foram reprovados três vezes; e que $4,1 \%$ tiveram mais de três reprovações. Estes dados sugerem que o motivo 'reprovação' pode indicar uma baixa interferência nas respostas da escala de opiniões.

Os dados referentes aos indicadores da escala de opiniões agrupadas em 15 categorias de avaliação são apresentadas a seguir. Esse grupo de categorias elencadas no presente estudo não pretende dar conta da complexidade do processo avaliativo, pois como afirma Dias Sobrinho (2002) a avaliação é um campo de grande complexidade, por ser pluri-referencial, polisêmica e multidimensional. Os dados são apresentados em relação à qualidade do impacto - positivo ou negativo - de cada um dos indicadores da escala de opinião, ao nível de interferência - muito ou pouco - dos mesmos indicadores, ao nível de significância entre a variáveis relacionadas com as respostas sobre a qualidade, e ao nível de significância entre a variáveis relacionadas com as respostas sobre a interferência. Vale lembrar que são destacados apenas os indicadores que apresentaram consenso entre as repostas dos informantes.

Nas tabelas apresentadas, são usadas as legendas 'p' e ' $R$ ', onde ' $p$ ' representa a significância estatística ou a probabilidade de algo ocorrer ao acaso. Conceitualmente, é tido como significativo quando seu valor é menor que 0,05 , o que significa uma probabilidade maior que $95 \%$ de ocorrer em função da análise observada. ' $R$ ' significa a relação entre duas variáveis - quanto mais próxima de $1,00(100 \%)$ mais perfeita tende a ser a relação entre elas. O valor de ' $R$ ' também pode ser negativo, indicando uma relação indireta. ' $R{ }^{2}$ ' significa a proporção da variabilidade. Ainda para a discussão dos dados decidiu-se pela exclusão das respostas 'Sem Opinião Formada' (SOF) para a qualidade do indicador ou para o seu nível de interferência.

\section{SOBRE A COORDENAÇÃO DO CURSO}

Os dados revelam que de modo geral, a maioria dos alunos está satisfeita com o tempo de dedicação presencial da pessoa responsável pela coordenação 
do Curso de Educação Física, embora não a julgue hábil na resolução dos problemas afetos ao Curso. O único consenso gerado nessa categoria referese ao tipo de relacionamento com os alunos $-82,2 \%$ dos alunos julgam este aspecto positivo.

Apenas o indicador referente ao clima de relacionamento provocado pela Coordenação alcançou consenso, onde $78,5 \%$ dos informantes julgam que este aspecto tem sido muito importante para a qualidade da formação do Curso de Educação Física, assim como 82,2\% consideram ser um aspecto positivo do Curso. Isso aponta para uma grande satisfação dos alunos em relação ao atendimento da coordenação destinado a eles.

Apenas um indicador apresentou associação com uma das variáveis independentes deste estudo. Este resultado revela que os alunos mais recentemente vinculados ao curso tendem a considerar que a competência da Coordenação pouco interfere na qualidade da formação oferecida. Este grupo pode estar divergindo da maioria dos informantes por não estarem tempo suficiente para o surgimento de problemas que demandem atenção da coordenação ou da administração. Apesar de a administração, que é uma das funções do coordenador do curso, ser a última dimensão que compõe a hierarquização da avaliação apresentada por Belloni et al (2000), ela não deixa de ter uma importância fundamental para o processo avaliativo dentro da complexidade do tema. A posição da maioria dos alunos apresentam essa importância quando avaliam de modo geral esse indicador como sendo importante para sua formação.

\section{SOBRE A ORGANIZAÇÃO CURRICULAR (DISCIPLINAS)}

Apenas cinco indicadores geraram níveis significativos de opiniões consensuais positivas em relação à organização curricular do curso. Os relacionados ao sistema de avaliação adotado pela Instituição $(78,8 \%)$, o nível de dificuldades das provas e dos trabalhos acadêmicos solicitados para verificação da aprendizagem (79\%), a articulação dos conhecimentos tratados nas disciplinas do currículo com as demandas do mercado de trabalho escolar $(76,6 \%)$, a articulação no trato do conhecimento abordado pelas diferentes disciplinas que compõem o currículo $(75,2 \%)$ e a carga horária destinada às disciplinas de fundamentação teórica $(71,3 \%)$. Isso reforça as informações prestadas pelos alunos do Curso que participaram da prova do ENADE no ano de 2007, onde a maioria das respostas indicaram que o currículo 'é bem integrado e há clara vinculação entre as disciplinas' e para aproximadamente $39 \%$ deles o currículo 'é relativamente integrado, já que as disciplinas se vinculam apenas por blocos ou áreas de conhecimento’. (BRASIL, 2007) 
Esse aspecto compõe a dimensão 'ensino de graduação', apresentado por Belloni et al (2000) como a principal dimensão a ser avaliada no desempenho institucional. Levando-se em conta a avaliação do corpo discente sobre esse aspecto, a instituição avaliada se posiciona em um alto conceito para o grupo pesquisado, atendendo ainda aos critérios indicados por Belloni et al (2000).

Em relação ao aspecto interferência na formação, quatro indicadores obtiveram consenso. A carga horária das disciplinas práticas de intervenção profissional $(78,1 \%)$, o nível de atualização dos conteúdos programáticos das disciplinas (73\%), a quantidade de alunos por turma (76,5\%) e a distribuição das disciplinas pelos oito períodos de formação do curso $(74,3 \%)$.

Numa avaliação realizada a partir da opinião dos alunos da Universidade do Vale do Itajaí (UNIVALI), 42\% dos alunos indicaram relevância dos conteúdos na formação profissional e 49\% responderam haver relativa relevância para a modalidade da formação em curso (UNIVALI, 1999). Comparando os resultados obtidos nas duas Instituições, as disciplinas do Curso de Educação Física da IES pesquisada são consideradas pelos alunos mais adequadas às demandas do mercado de trabalho.

Os resultados sugerem que quanto mais baixo for o período de vinculação do informante, maior é a possibilidade de indicação de impacto negativo dos indicadores 'Nível de atualização das bibliografias' e 'Flexibilização curricular para os alunos com dificuldades de aprendizagem (acompanhamento especial, tutorias)'.

Tabela 1: Relação das variáveis com indicadores da organização curricular na coluna B

\begin{tabular}{lcccc}
\hline \multicolumn{1}{c}{ Indicador } & Variável & $\mathbf{p}$ & $\mathbf{R}$ & $\mathbf{R}^{\mathbf{2}}$ \\
\hline $\begin{array}{l}\text { Adequação das disciplinas com as exigências do mer- } \\
\text { cado de trabalho escolar }\end{array}$ & período & 0,009 & 0,13 & 0,017 \\
$\begin{array}{l}\text { Distribuição das disciplinas ao longo do Curso de } \\
\text { Educação Física }\end{array}$ & período & 0,02 & 0,12 & 0,013 \\
$\begin{array}{l}\text { Planejamento de dias e horários da oferta de disciplinas } \\
\begin{array}{l}\text { Flexibilização curricular para os alunos com dificuldades } \\
\text { de aprendizagem (acompanhamento especial, tutorias) }\end{array}\end{array}$ & período & 0,009 & 0,13 & 0,017 \\
$\begin{array}{l}\text { Mecanismos recuperação dos alunos com dificuldades } \\
\text { de aprendizagem (PAP e monitoria) }\end{array}$ & período & 0,001 & 0,12 & 0,015 \\
\hline
\end{tabular}

Os indicadores listados na Tabela 2 indicam que quanto mais recente é o ingresso no curso, maior é a tendência dos informantes considerarem que pouco 
interferem na qualidade da formação oferecida. Estas respostas podem indicar que este grupo de alunos ainda não tem experiência suficiente para avaliar os referidos indicadores.

\section{SOBRE OS ESTÁGIOS SUPERVISIONADOS OBRIGATÓRIOS}

Nesta categoria não houve consenso entre as opiniões dos informantes no que se refere à qualidade dos indicadores na sua formação. Por outro lado há consenso sobre o nível de interferência em todos os indicadores relacionados ao estágio supervisionado para a formação acadêmico-profissional dos alunos do Curso de Educação Física.

Tabela 2: Relação das variáveis com indicadores do estágio supervisionado na coluna A

\begin{tabular}{lcccc}
\hline \multicolumn{1}{c}{ Indicador } & Variável & $\mathbf{p}^{*}$ & $\mathbf{R}$ & $\mathbf{R}^{\mathbf{2}}$ \\
\hline \hline $\begin{array}{l}\text { Formulários de registro das atividades de } \\
\text { Estágio }\end{array}$ & período & 0,0003 & 0,18 & 0,032 \\
& reprovação & 0,008 & 0,22 & 0,048 \\
$\begin{array}{l}\text { Quantidade de alunos por orientador de } \\
\text { Estágio }\end{array}$ & período & 0,0000 & 0,26 & 0,068 \\
$\begin{array}{l}\text { Experiências vivenciadas em função das } \\
\text { exigências do mercado de trabalho escolar }\end{array}$ & período & 0,0000 & 0,32 & 0,097 \\
& período & 0,0000 & 0,27 & 0,075 \\
Carga horária do Estágio Supervisionado & turno & 0,04 & 0,29 & 0,084 \\
\hline \hline
\end{tabular}

A associação dos quatro indicadores apresentados acima indica que quanto mais recente é a vinculação do aluno ao curso, maior é a sua associação com as respostas negativas. Este resultado é previsível, na medida em que as atividades de estágio supervisionado são destinadas aos alunos a partir da segunda metade do curso e esse grupo de informantes ainda não chegou nessa fase.

A avaliação dos formulários de registro das atividades de estágio supervisionado também está significativamente associada aos alunos com maior número de reprovações, que possuem a maior tendência a avaliarem negativamente este aspecto.

Verificou-se, também, uma significativa associação com os alunos do turno da noite, que julgaram positivamente a carga horária de estágio supervisionado. 
Tabela 3: Relação das variáveis com indicadores do estágio supervisionado na coluna B

\begin{tabular}{lcccc}
\hline \multicolumn{1}{c}{ Indicador } & Variável & $\mathbf{p}^{*}$ & $\mathbf{R}$ & $\mathbf{R}^{2}$ \\
\hline \hline $\begin{array}{l}\text { Formulários de registro das atividades de } \\
\text { Estágio }\end{array}$ & período & 0,000007 & 0,22 & 0,048 \\
\hline $\begin{array}{l}\text { Quantidade de alunos por orientador de } \\
\text { Estágio }\end{array}$ & período & 0,0000 & 0,27 & 0,072 \\
$\begin{array}{l}\text { Oferta de locais para realização de Estágio } \\
\text { Supervisionado }\end{array}$ & período & 0,0000 & 0,31 & 0,096 \\
\cline { 2 - 5 } & turno & 0,03 & 0,33 & 0,11 \\
$\begin{array}{l}\text { Experiências vivenciadas em função das } \\
\text { exigências do mercado de trabalho escolar }\end{array}$ & período & 0,0000 & 0,30 & 0,091 \\
\cline { 2 - 5 } & turno & 0,01 & 0,32 & 0,11 \\
$\begin{array}{l}\text { Experiências vivenciadas em função das exi- } \\
\text { gências do mercado de trabalho não-escolar }\end{array}$ & período & 0,0000 & 0,29 & 0,086 \\
\cline { 2 - 5 } & turno & 0,02 & 0,31 & 0,098 \\
Carga horária do Estágio Supervisionado & período & 0,000001 & 0,24 & 0,058 \\
\cline { 2 - 5 } & turno & 0,004 & 0,28 & 0,078 \\
\hline
\end{tabular}

A Tabela 3 revela que a variável referente ao período de vinculação dos alunos com o Curso de Educação Física apresenta associação significativa com os seis indicadores desta categoria de análise. Os alunos dos primeiros períodos, certamente por desconhecerem a estrutura e o funcionamento das atividades de estágio supervionado, tendem a julgar os indicadores pouco importantes para a formação deles. Os resultados informam ainda que os alunos matriculados nos turnos da tarde e da manhã tenderam a conferir pouca importância dos indicadores apresentados acima.

\section{SOBRE AS PRÁTICAS PEDAGÓGICAS OBRIGATÓRIAS COMO COMPONENTE CURRICULAR}

Além de apresentar consenso entre os informantes nesse único indicador da categoria, a 'Carga horária destinada às práticas pedagógicas no contexto das disciplinas' se apresenta como positivo na formação acadêmico-profissional dos alunos. Os dados ainda revelam que houve consenso de que a carga horária das práticas pedagógicas está influenciando muito para uma boa formação dos alunos. Nesta categoria não foi encontrada relação significativa entre as variáveis independentes e o indicador avaliado. 


\section{SOBRE OS TRABALHO DE CONCLUSÃO DE CURSO}

Sobre essa categoria os dados revelam que não há consenso em relação ao nível de interferência dos indicadores. Entretanto, todos os indicadores foram consensualmente considerados muito importantes para a formação recebida, mesmo que para a maior parte deles esta ainda seja uma disciplina distante do seu período de vinculação no curso.

Tabela 4: Relação das variáveis com indicadores do trabalho de conclusão de curso na coluna $A$

\begin{tabular}{llccc}
\hline \multicolumn{1}{c}{ Indicador } & Variável & $\mathbf{p}$ & $\mathbf{R}$ & $\mathbf{R}^{\mathbf{2}}$ \\
\hline Mecanismos de orientação do TCC & período & 0,0003 & 0,18 & 0,032 \\
Divulgação do TCC & período & 0,002 & 0,15 & 0,024 \\
Quantidade de alunos por orientador de TCC & período & 0,01 & 0,12 & 0,016 \\
\hline
\end{tabular}

Em relação aos indicadores acima apresentados, os alunos mais recentemente vinculados ao curso, têm maior tendência a considerará-los negativos na qualidade do curso. Como ainda não tiveram contato com a disciplina, essa avaliação pode indicar a influência de opiniões de alunos insatisfeitos com a disciplina, ou ainda, indicar uma avaliação descompromissada por parte do informante no momento do preenchimento do instrumento de coleta de dados.

Tabela 5: Relação das variáveis com indicadores do trabalho de conclusão de curso na coluna B

\begin{tabular}{llccc}
\hline \multicolumn{1}{c}{ Indicador } & Variável & $\mathbf{p}$ & $\mathbf{R}$ & $\mathbf{R}^{\mathbf{2}}$ \\
\hline \hline Mecanismos de orientação do TCC & período & 0,0001 & 0,19 & 0,036 \\
Divulgação do TCC & período & 0,0006 & 0,17 & 0,029 \\
Quantidade de alunos por orientador de TCC & período & 0,000003 & 0,23 & 0,053 \\
\hline
\end{tabular}

De acordo com os dados apresentados na Tabela 5 os alunos mais novos do curso tendem a julgar estes aspectos como sendo pouco importantes para a formação oferecida. Aqui novamente os alunos mais novos demonstram o não conhecimento do processo de ensino e pesquisa que as instituições de ensino superior devem levar a cabo. O Trabalho de conclusão de curso abarca parte desse processo de produção do conhecimento e iniciação científica, tarefa essa 
ressaltada por Dias Sobrinho (2003), quando afirma que uma das tarefas da Universidade é a produção de conhecimento científico.

\section{SOBRE AS ATIVIDADES COMPLEMENTARES OBRIGATÓRIAS}

$\mathrm{O}$ único indicador que alcançou consenso diz respeito aos mecanismos institucionais de incentivo à realização dessas experiências, indicando que os alunos insatisfeitos são $72,1 \%$.

$\mathrm{O}$ indicador tem uma associação significativa, onde quanto mais recente é a data de ingresso no curso maior é a tendência de julgar positivo este aspecto. Este dado reforça a suposição de que as instituições estejam se adequando gradativamente a este novo tipo de exigência e os alunos mais novos já devem estar se beneficiando dessa nova exigência.

De acordo com os dados da pesquisa a 'Divulgação do Regulamento e da dinâmica das Atividades Complementares' é considerada pelos alunos do turno da tarde e principalmente os do turno da manhã tendem como pouco importante. Esse resultado pode indicar o desconhecimento desse grupo de alunos sobre a obrigatoriedade e s implicações desse indicador sobre a sua formação.

\section{SOBRE O DESEMPENHO DOS ALUNOS NO ENADE (EXAME NACIONAL DE AVALIAÇÃO DO DESEMPENHO DOS ESTUDANTES)}

Segundo o SINAES (BRASIL, 2007) o ENADE é um instrumento de avaliação institucional de aplicação nacional, que objetiva identificar adequadas estratégias de políticas públicas e dos gestores para a melhoria da qualidade do ensino. Entretanto Dias Sobrinho (2003) enfatiza que esse tipo de exame nacional deve priorizar o processo de aprendizagem, respeitando-se as diferentes características culturais e regionais do discente avaliado.

Apenas o indicador 'Atividades promovidas pelo Curso em função dos resultados do ENADE' apresentou consenso positivo de 77,3\%, demonstrando um empenho na aplicação de políticas de melhoria das atividade baseadas nos resultados anteriores. A exemplo do que ocorreu com a categoria anterior, não houve consenso entre os informantes sobre o nível de importância destes indicadores, indicando que o significado da avaliação e sua forma de aplicação não estão muito claros para os alunos.

Os indicadores 'Esclarecimentos aos alunos sobre o ENADE' e 'Atividades promovidas pelo Curso em função dos resultados do ENADE', a resposta 'Pouco' está mais associada com os turnos da tarde e da manhã. Esse dados demonstram uma oposição em relação a maioria dos informantes que apontaram essa categoria como sendo muito importante para a sua formação acadêmico- 
profissional. Esse dado reforça a necessidade de um maior esclarecimento sobre os objetivos dessa avaliação e de sua importância para a formação do aluno.

\section{SOBRE O CORPO DOCENTE}

Destacam-se como positivos e consensuais o relacionamento professoraluno, o nível de formação acadêmica dos professores, a competência para conduzir o processo de ensino-aprendizagem, o domínio e atualização dos conhecimentos que são objeto de ensino-aprendizagem, a experiência profissional com os assuntos pertinentes à disciplina ministrada e, por fim, aspectos formais como assiduidade e pontualidade. Esses indicadores seguem em concordância aos apresentados por Dias Sobrinho (2003) como importante na avaliação do corpo docente. Este autor apresenta a importância de se avaliar multidimensionalmente o docente, pois seu espectro de ação é amplo.

No estudo realizado por Nascimento et al (2005), os resultados revelaram uma insatisfação da maioria dos alunos em relação à competência dos professores para lecionar suas disciplinas, resultado oposto ao da presente pesquisa. O estudo realizado na Faculdade São Camilo (FSCES), no Espírito Santo, os alunos também demonstraram insatisfação com a dinâmica das aulas (DARDENGO, 2007). Esta variação de resultados pode demonstrar diferenças das ações pedagógicas e de formação dos professores em instituições com perfis diferenciados.

De forma ampla a categoria Corpo docente é positivamente avaliada pelo corpo discente do Curso de Educação Física estudado. Todos os indicadores registraram consenso de opinião, demonstrando grande importância dessa categoria para a formação dos informantes. Este fato atende ao que posto por Dardengo (2007) quando afirma que os alunos têm expectativas altas quanto ao desempenho desses professores no sentidos de lhes ofertar um produto de qualidade, que neste caso é o ensino e uma aprendizagem adequada à incersão no mercado de trabalho.

O indicador 'incentivo para a dedicação aos estudos' foi considerado negativo pelos alunos mais velhos. Esse dado pode demonstrar um não amadurecimento destes alunos, pois um dos fins do ensino superior é gerar a autonomia em seu corpo discente para conduzir a sua vida acadêmica.

Em relação ao nível de intereferência, apenas o indicador 'Domínio e atualização do conhecimento em relação à disciplina' revelou associação significativa. Quanto mais recente é a vinculação dos alunos, maior é a tendência a julgarem pouco interferente na qualidade do curso. Isso pode se dever a ainda falta de entendimento sobre a importância do nível de conhecimento e atualização de 
um professor frente a uma disciplina a ser cursada. Essas respostas demonstram uma tendência contrária às respostas dadas pela maioria dos informantes $(87,7 \%)$, que afirmam consensualmente que esse indicador é muito importante para a sua formação.

\section{SOBRE O CORPO DISCENTE}

O indicador 'Relacionamento entre os alunos' obteve índice de consenso positivo entre os informantes. Por outro lado a participação dos alunos nas atividades e eventos promovidos por outras instituições gerou consenso negativo. Este resultado pode sugerir falta de disponibilidade de tempo ou financeiras para participação em atividades fora da sua instiuição, ou ainda pode sugerir que a divulgação desses eventos não é satisfatória.

Todos os indicadores foram considerados muito importantes para a formação acadêmico-profissional dos alunos. Entretanto, somente o relacionamento entre eles registrou um índice consensual de acordo entre 76,3\% dos informantes. Sobre isso Dias Sobrinho (2002, p.65) afirma que na atualidade o "valor supremo é o individualismo [...] A noção de alteridade e de socialidade aí é esvaziada". Deste modo o corpo discente se apresenta de forma contrária ao fluxo corrente.

Apenas o indicador 'Participação nas atividades regulares do Curso (aulas e eventos da instituição)' aparece significativamente associado à variável período. Os informantes mais novos do curso foram os que mais responderam que esse indicador tem pouca importância na sua formação.

\section{SOBRE O CORPO TÉCNICO-ADMINISTRATIVO}

Os indicadores desta categoria não foram consensuais apesar de serem considerados de impacto positivo na qualidade do curso. Em relação ao nível de interferência, há consenso que a competência do corpo administrativo e a forma de se relacionar com os alunos estejam interferindo muito na qualidade da formação recebida. Não houve associações significativas para essa categoria.

\section{SOBRE A BIBLIOTECA}

Dos oito indicadores referentes à biblioteca apenas três apresentam avaliação positiva, e desses, dois indicadores apresentaram índices de consenso, a saber: 'Atendimento dos funcionários da biblioteca' (79,9\%) e 'Limpeza, de conservação e de manutenção da biblioteca e do acervo' (84,6\%). Os demais indicadores obtiveram avaliação negativa. Vale ressaltar que a maioria dos informantes não freqüentam bibliotecas em outros locais, demonstrando pouco conhecimento para emitir uma avaliação mais consistente. 
Tabela 6: Relação das variáveis com indicadores da biblioteca na coluna $B$

\begin{tabular}{|c|c|c|c|c|}
\hline Indicador & Variável & $\mathbf{p}$ & $\mathbf{R}$ & $\mathbf{R}^{2}$ \\
\hline \multirow{2}{*}{$\begin{array}{l}\text { Quantidade, diversidade e atualização de li- } \\
\text { vros necessários ao curso de Educação Física }\end{array}$} & período & 0,005 & 0,14 & 0,020 \\
\hline & faixa-etária & 0,004 & 0,20 & 0,040 \\
\hline $\begin{array}{l}\text { Quantidade, diversidade e atualização de } \\
\text { livros e revistas científicas necessários os } \\
\text { curso de Ed. Física }\end{array}$ & período & 0,03 & 0,11 & 0,011 \\
\hline $\begin{array}{l}\text { Quantidade, diversidade e atualização de } \\
\text { outras fontes de consulta (jornais, revistas, } \\
\text { CDs, vídeos etc.) }\end{array}$ & período & 0,002 & 0,15 & 0,023 \\
\hline Sistema de pesquisa ao acervo bibliográfico & período & 0,006 & 0,14 & 0,019 \\
\hline
\end{tabular}

Os indicadores apresentados acima tendem a ser julgados como pouco importantes em termos de interferência na qualidade do curso pelos alunos dos períodos iniciais. Os informantes mais velhos se associaram significativa com o indicador quantidade, diversidade e atualização de livros necessários ao curso de Educação Física, julgando-o como pouco interferente na qualidade da formação.

Verificando os dados apresentados pelo ENADE (2007) do curso pesquisado identificou-se que muitos alunos ingressantes freqüentam raramente a biblioteca $(37,7 \%)$ o que vai de encontro aos dados encontrados na Tabela 6. Entretanto os alunos concluintes também apresentam um alto índice de não freqüência $(7,4 \%)$ ou pouca frequência da biblioteca $(26,3 \%)$. Isso pode indicar que os dados fornecidos pelos informantes que não se caracterizam como ingressantes ou concluintes pode interferir nessa análise comparativa, pois não são contemplados pelos dados do ENADE.

\section{SOBRE O LABORATÓRIO DE INFORMÁTICA}

Essa categoria apresentou índice consensual de qualidade negativa para a formação em todos os indicadores. Esses dados demonstram uma grande insatisfação com o laboratório de informática. Nascimento et al (2005) também identificaram insatisfação dos alunos do Curso de Graduação em Educação Física da UFSC com o laboratório de informática. A partir desses dados podemos identificar que em ambas as instituições, não se consegue atender as demandas dos alunos por equipamentos do laboratório de informática. Isso pode apontar para a pressão exercida pelo mercado de informática frente aos constantes lançamentos de novas tecnologias e inovações.

Somente o indicador acesso à Internet para realização das tarefas acadêmicas obteve índice de consenso, indicando ser muito importante para a formação dos informantes. 
Os informantes matriculados mais recentemente no curso são os que julgaram positiva a 'Quantidade, a qualidade e a manutenção dos equipamentos de informática’.

Estes resultados revelam que os alunos matriculados nos primeiros períodos do curso são aqueles que mais julgaram os indicadores 'Instalações do laboratório de informática' e 'Quantidade, qualidade e manutenção dos equipamentos de informática' como pouco interferentes na qualidade do curso. Essas respostas são contrárias a da maioria dos informantes que ressaltou a grande importância desses indicadores. Isso é reforçado pela grande freqüência com a qual os alunos utilizam o microcomputador segundo dados do ENADE (2007), onde mais que $40 \%$ de ingressantes e concluíntes usam sempre o computador.

\section{SOBRE AS INSTALAÇÕES GERAIS DA UNIDADE PESQUISADA}

Os dados revelaram impacto de tendência positiva na qualidade do curso. Dos quatro indicadores, três obtiveram níveis de consenso - 'Adequação das salas de aula', as 'Condições de limpeza, conservação e manutenção das instalações em geral' e dos banheiros em especial.

Em relação à adequação das salas de aula, o estudo realizado na UNIVALI apresentou percentual de $73 \%$ de respostas 'Sim' para adequação desse espaço físico (UNIVALI, 1999), resultado similar ao encontrado na IES pesquisada. Isso demonstra que ambas instituições buscam adequar suas instalações as demandas de seus alunos. Os dados são reforçados pelo ENADE (2007) que apresenta uma alta satisfação com esses indicadores, onde mais de $50 \%$ dos ingressantes e concluintes julgaram esse aspecto positivamente.

Todos os indicadores foram considerados muito interferentes na qualidade do curso, alcançando consenso para todos eles. Essa avaliação conjugada com os dados sobre o impacto caracteriza as instalações gerais como sendo um aspecto positivo do curso e muito interferente na formação dos informantes.

O indicador 'Adequação dos setores de atendimento aos alunos' se vincula significativamente com os informantes mais novos no curso, que julgaram como positivo esse indicador. $\mathrm{O}$ indcador 'Condições de higiene dos banheiros' tem associação com os alunos matriculados nos turnos da tarde e da noite, que tenderam a considerá-lo de impacto negativo, opinião esta contrária à da maioria dos informantes.

\section{SOBRE OS RECURSOS MATERIAIS E INSTALAÇÕES ESPECÍFICAS DO CURSO}

O indicador 'condições de limpeza, conservação e manutenção dos materiais e das instalações específicas do curso' foi o único que gerou índice de consenso 
(77,3\%), indicando impacto positivo. Na avaliação realizada pela UNIVALI, o julgamento sobre as instalações destinadas às aulas práticas apresentou resultados diferentes do encontrado nesta pesquisa. Para 38\% dos informantes daquela instituição as instalações são inadequadas, e para 28\% são consideradas adequadas em parte. (UNIVALI, 1999)

A avaliação da categoria Recursos materiais e instalações especificadas da IES pesquisada se apresentou como sendo positiva, reforçando o que foi verificado no relatório do ENADE (2007) referente à instituição foco desta pesquisa.

Todos os indicadores desta categoria foram considerados muito interferentes na qualidade do curso, além de terem apresentado índices de consenso entre os informantes.

Os resultados revelam que, quanto mais recente é o período de vínculo dos alunos no curso, maior é a tendência do indicador 'Locais destinados às aulas práticas' ser julgado como gerador de impacto positivo para a qualidade da formação.

\section{SOBRE OS SERVIÇOS GERAIS PRESTADOS PELA INSTITUIÇÃO}

Nesta categoria, a facilidade de acesso foi o único a alcançar consenso positivo de $72,0 \%$ na opinião dos alunos. Por sua vez, os resultados obtidos a partir da opinião dos alunos acerca do nível de interferência, cinco indicadores alcançaram consenso, sendo eles: 'Serviços de reprodução de documentos e material didático (xerox)' (77,8\%), o 'Valor das mensalidades' (76,7\%), os 'Mecanismos adotados para facilitar o pagamento das mensalidades (Bolsas, descontos, negociações, etc.)' (78,0\%), a 'Facilidade de acesso à Unidade do Curso' (81,5\%) e a 'Imagem do Curso de Graduação Educação Física da IES pesquisada no mercado de trabalho' $(79,9 \%)$.

Tabela 7: Relação das variáveis com indicadores dos serviços gerais prestados pela IES na coluna $A$

\begin{tabular}{llccc}
\hline \multicolumn{1}{c}{ Indicador } & Variável & $\mathbf{p}$ & $\mathbf{R}$ & $\mathbf{R}^{\mathbf{2}}$ \\
\hline $\begin{array}{l}\text { Serviços de alimentação } \\
\text { Serviços de estacionamento }\end{array}$ & período & 0,00005 & 0,20 & 0,04 \\
$\begin{array}{l}\text { Serviços de reprodução de do- } \\
\text { cumentos e material didático } \\
\text { (xerox) }\end{array}$ & período & 0,006 & 0,14 & 0,019 \\
\hline
\end{tabular}

Os indicadores apresentados acima se relacionam significativamente com os alunos mais recentes no curso, com respostas de impacto positivo. Nesta categoria não se verificou associação significativa entre as variáveis indepen- 
dentes e os respectivos indicadores, no que se refere ao nível de interferência na qualidade do curso.

\section{CONSIDERAÇÕES FINAIS}

De modo geral, não foi possível apresentar análises comparativas mais amplas com os estudos de objetivos similares. Os poucos estudos existentes até a data da realização do presente estudo são muito recentes, provavelmente em decorrência na recém implantada sistemática da avaliação instituicional do ensino superior brasileiro. Alguns estudos sobre a avaliação do ensino superior apontam a utilização do corpo discente apenas para avaliar o corpo docente, como é o caso do Centro Universitário São Camilo (DARDENGO, 2007), da Universidade Federal Fluminense (PAULA, 2004), o da Universidade Federal do Rio de Janeiro e da Universidade de São Paulo (PAULA, 2002). Entretanto, somente no estudo de Dardengo (2007) ofereceu subsídios para uma análise comparativa dos resultados sobre o corpo docente.

Nos estudos consultados não se identificou um tratamento estatístico que privilegiasse a análise comparativa do nível de significância de variáveis, como as aqui apresentadas, pois os referidos estudos se detiveram em análises estatísticas descritivas.

Os dados obtidos no presente estudo indicaram que dos 76 indicadores distribuídos em 15 categorias, 61,9\% foram considerados como geradores de impacto positivo enquanto que $38,1 \%$ foram julgados como causadores de impacto negativo na qualidade do Curso. No geral, estes resultados sugerem que os alunos estão satisfeitos com o curso. No entanto, apenas 34,2\% geraram índices de consenso, sendo $27,6 \%$ considerados de impacto positivo e $6,6 \%$ de impacto negativo. Em termos de consenso, também prevalece uma tendência de avaliação positiva da qualidade do curso, segundo a opinião do corpo discente.

No que se refere ao nível de interferência dos indicadores de análise na qualidade da formação acadêmico-profissional, os resultados revelaram que todos $(100 \%)$, estão interferindo muito na qualidade do curso. Porém, um pouco mais da metade desses indicadores (54\%) foram considerados como opiniões consensuais.

Mas no contexto da presente pesquisa e em termos de índices de consenso, a análise do nível de interferência de cada indicador só ganha força se conjugado com o tipo de impacto gerado. Dos 76 indicadores, apenas 22 deles $(28,9 \%)$ geraram índices de consenso tanto em relação ao tipo de impacto quanto em relação ao nível de interferência, envolvendo $10(67,0 \%)$ das 15 categorias de análise.

Do ponto de vista consensual, o único aspecto apontado como negativo e que está interferindo muito na qualidade da formação recebida refere-se ao 
laboratório de informática. Entretanto, muitos deles freqüentam o laboratório de Informática para consultar e-mail, entrar no site de relacionamento orkut e navegar em sites que nada tem a ver com a produção acadêmica e apoio aos estudos vinculados ao curso.

Os resultados do presente estudo revelaram informações relevantes para o processo de avaliação e auto-avaliação do curso de Educação Física da IES pesquisada. Estudos desta natureza são importantes para instituições e cursos comprometidos com a qualidade do processo formativo.

No entanto, os resultados de pesquisas desta natureza não asseguram, por si só, a fiel radiografia da realidade focalizada, apenas se constituem em informações relevantes que precisam ser cruzadas com as informações dos demais atores sociais que interagem na instituição e no curso. Trata-se, do ponto de vista de um importante segmento de um cenário formativo, a quem se destina a função político-social de uma instituição educacional - os alunos.

\section{REFERÊNCIAS}

AFONSO, M. R. Aspectos interferentes na qualidade dos programas de mestrado em Educação Física no Brasil: um estudo descritivo1992. Dissertação (Mestrado em educação física) - Universidade Gama Filho. Rio de Janeiro, 1992.

ALI, Amal K. Using the Delphi technique to search for empirical measure of local planning agency power. Brock University: The Qualitative Report, v. 10, n. 4, p. 718-744, dec. 2005.

BALZAN, N. C. A voz do estudante: sua contribuição para a deflagração de um processo de Avaliação Institucional. In DIAS SOBRINHO, J.; BALZAN, N. C. (Orgs.). Avaliação institucional: teoria e experiências. 2. ed. São Paulo: Cortez, 2000.

BELLONI, I.; BELLONI, J. A.; BORGES, M.M.; SOBRAL, D.T. Avaliação institucional da Universidade de Brasília. In: DIAS SOBRINHO, J.; BALZAN, N.C. (Orgs.). Avaliação institucional: teoria e experiências. 2. ed. São Paulo: Cortez, 2000.

BRASIL. MEC. INEP. Lei No 10.861, DE 14 DE ABRIL DE 2004. (Publicado no DOU de 15/04/2004, Seção, p.3-4).

. Congresso Nacional. Lei No 9394 de 20 de dezembro de 1996. (DOU de 23 de dezembro de 1996). INEP, 2009.

INEP. Censo da educação superior 2008: resumo técnico. Brasília:

. INEP. Enade 2007: relatório do curso de educação física do Centro Universitário da Cidade. Brasília: INEP, 2008. 
DARDENGO, Vilma Maria. Avaliação institucional: a tessitura de uma experiência. São Paulo: Centro Universitário São Camilo, 2007.

DIAS SOBRINHO, José. Avaliação: políticas educacionais e reforma da educação superior. São Paulo: Cortez, 2003

Universidade e avaliação: entre a ética e o mercado. Florianópolis: $\overline{\text { Insular, } 2002 .}$

HANASHIRO, Darcy Mitiko Mori; NASSIF, Vânia Maria Jorge; TEIXEIRA, Maria Luisa Mendes. O papel dos profissionais de recursos humanos na universidade compartilhado pelos diferentes Stakeholders: revelando as competências docentes. FACEF pesquisa, São Paulo, v. 6, n. 3, p. 63-77, setembro/dezembro. 2003.

LINSTONE, Harold A.; TUROFF, Murray (Editors). The delphi method: techniques and applications. Reading, MA: Addison-Wesley Publishing Company, 1975.

NASCIMENTO, Juarez Vieira do. Escala de auto-percepção de competência profissional em educação física e desportos. Revista Paulista de Educação Física, São Paulo, v. 13, n. 1, p. 5-21, jan./jun. 1999.

NASCIMENTO, Juarez Vieira do; NAHAS, Markus Vinicius; MENDES, Evandra Hein. Avaliação da formação inicial em educação física na UFSC: um estudo delphi.In: CONGRESSO INTERNACIONAL DE PEDAGOGIA DO ESPORTE, 2., 2005, Maringá. Anais do II Congresso Internacional de Pedagogia do Esporte, Maringá, 2005. v. 2, p.32-40.

OLARTE, Carlos Eduardo Vargas. Plan local del deporte, la recreación y la educación física del municipio de Santiago de Cali: deporte en las metrópolis del siglo XXI. Cali: SFBD/Estudio A y C, 2006.

PAULA, Maria de Fátima de. A modernização da universidade e a transformação da intelligentzia universitária. Florianópolis: Insular, 2002.

PAULA, Maria de Fátima de (Org.). Debatendo a universidade: subsídios para a reforma universitária. Florianópolis: Insular, 2004.

SAETA, Beatriz Regina Pereira; POPADIUK, Silvio; TEIXEIRA, Maria Luiza Mendes. Avaliação de serviços educacionais no ensino superior: o ponto de vista de alunos regulares e vestibulandos portadores de deficiência. O\&S, São Paulo, v. 10, n. 27, maio/agosto. 2003.

THOMAS, J. R., NELSON, J. K. Métodos de pesquisa em educação física. 3 ed. São Paulo: Artmed, 2002.

UNIVALI. Avaliação Institucional na UNIVALI: ouvindo os egressos em 1996. Itajaí: UNIVALI, 1999. 